\title{
Usefulness of anti-vascular endothelial growth factor combined with dexamethasone implant for retinal vein occlusion
}

\section{Moosang Kim}

Department of Ophthalmology, School of Medcine, Kangwon National University, Chuncheon, Kangwon, Korea
Correspondence: Moosang Kim Department of Ophthalmology, School of Medicine, Kangwon National University,

156 Baengnyeong-ro, Chuncheon,

Kangwon 200-722, Korea

Tel +82 332582014

Fax +82 332582000

Email kimmoo-79@hanmail.net
This article was published in the following Dove Press journal:

Clinical Interventions in Aging

14 October 2016

Number of times this article has been viewed

\section{Dear editor}

I read with great interest the recent study by Michalska-Małecka et al ${ }^{1}$ published in the journal Clinical Interventions in Aging. The authors investigated the impact of intravitreal dexamethasone implant on macular morphology and functions in eyes with macular edema (ME) secondary to branch retinal vein occlusion (BRVO) or central retinal vein occlusion (CRVO). I congratulate the authors for their enlightening study and would like to make some contributions to the study.

When treating BRVO or CRVO, first-line treatment is typically an anti-vascular endothelial growth factor (VEGF) agent. If this is inadequate, steroids can be initiated, either in combination with the anti-VEGF agent or alone. Steroids have significant anti-inflammatory actions that may incrementally benefit anti-VEGF blockade for the treatment of edema due to retinal vein occlusion (RVO). Dexamethasone intravitreal implants have also been shown to be a safe and effective treatment option. A recent study evaluated the safety and efficacy of one or two treatments over 12 months in eyes with ME related to BRVO or CRVO. ${ }^{2}$

However, I believe that combination therapy is very advantageous in patients with RVO. A recent study found that bevacizumab combined with dexamethasone implants produced greater improvements in macular thickness than bevacizumab therapy alone and required fewer bevacizumab injections in cases of both BRVO and CRVO. ${ }^{3}$ For patients who are already pseudophakic and who are not steroid responders, adding dexamethasone implant to a regimen of anti-VEGF injections is unlikely to significantly increase the risk of complications; less frequent treatments with combination therapy may be a palatable alternative to the more frequently administered anti-VEGF monotherapy.

I think that many doctors stick with anti-VEGF monotherapy longer than they should. Typically, patients' response to anti-VEGF injections is evident early in the course of treatment. If patients show the inadequate response, I add the dexamethasone implant very early. I look forward to further studies that will better define the role of anti-VEGF combined with dexamethasone implant.

\section{Disclosure}

The author reports no conflict of interest in this communication. 


\section{References}

1. Michalska-Małecka K, Gaborek A, Nowak M, Halat T, Pawłowska M, Spiewak D. Evaluation of the effectiveness and safety of glucocorticoids intravitreal implant therapy in macular edema due to retinal vein occlusion. Clin Interv Aging. 2016;11:699-705.

2. Haller JA, Bandello F, Belfort R Jr, et al; Ozurdex GENEVA Study Group. Dexamethasone intravitreal implant in patients with macular edema related to branch or central retinal vein occlusion: twelve-month study results. Ophthalmology. 2011;118(12):2453-2460.
3. Maturi RK, Chen V, Raghinaru D, Bleau L, Stewart MW. A 6-month, subject-masked, randomized controlled study to assess efficacy of dexamethasone as an adjunct to bevacizumab compared with bevacizumab alone in the treatment of patients with macular edema due to central or branch retinal vein occlusion. Clin Ophthalmol. 2014;8: $1057-1064$. 


\section{Authors' reply}

Katarzyna Michalska-Małecka ${ }^{1,2}$

Aneta Gaborek ${ }^{2}$

Mariusz Nowak ${ }^{3}$

Tomasz Halat ${ }^{4}$

Mariola Pawłowska²

Dorota Śpiewak ${ }^{2}$

'Department of Ophthalmology, School of Medicine in Katowice, ${ }^{2}$ University Clinical Center, University Hospital, Medical University of Silesia, Katowice, ${ }^{3}$ Pathophysiology Division, Department of Pathophysiology and Endocrinology, Medical University of Silesia, School of Medicine with Division of Density, Zabrze, ${ }^{4}$ Education and Medical Simulation Center, Medical University of Silesia,

Katowice, Poland

Correspondence: Katarzyna Michalska-Małecka

Department of Ophthalmology, School of Medicine in Katowice, Medical University of Silesia, Ceglana Street 35, Katowice 40-952, Poland

Tel +4832358 I280

Email k.michalska.malecka@gmail.com

\section{Dear editor}

Thank you kindly for the letter. We are very pleased that you were interested in our article and the results of the research and that it caused your reflection on the choice of the most effective therapy of macular edema (ME) secondary to retinal vein occlusion (RVO).

In our research, we have evaluated the effectiveness of intravitreal dexamethasone implant in the treatment of ME secondary to branch retinal vein occlusion and central retinal vein occlusion. The improvement in best-corrected visual acuity and the decrease in central retinal thickness persisted in majority of patients up to 6 months of observation, although the best outcomes were observed within the first half of this period. Three months after dexamethasone implantation, the improvement in the above parameters was not so significant. During the last examination in some patients, we have noted slow recurrence of retinal edema even though the cathode-ray tube parameters were still lower than parameters obtained before administration of dexamethasone implant. It seems that the perfect time to implement subsequent therapy is when there occurs thickening of the retina. In the light of reports on the effectiveness of anti-vascular endothelial growth factor (VEGF) medications, such injections might be applied then.

The results of RVO are long-lasting and require many months of treatment, which is burdensome for the patient. Thus, it is crucial to look for solutions that will allow the effects to be maintained for a longer time and the amount of injections to be reduced. Therefore, combination of antiVEGF injections and dexamethasone implant, which you mentioned, is a legitimate suggestion. We wish to emphasize the need to consider the course and method of treatment individually depending on clinical case. Moreover, there is a need to adopt standards of treatment of RVO, taking into account current therapeutic options, ie, anti-VEGF, corticosteroids and laser therapy.

\section{Disclosure}

The authors report no conflicts of interest in this communication.

Dove Medical Press encourages responsible, free and frank academic debate. The content of the Clinical Interventions in Aging 'letters to the editor' section does not necessarily represent the views of Dove Medical Press, its officers, agents, employees, related entities or the Clinical Interventions in Aging editors. While all reasonable steps have been taken to confirm the content of each letter, Dove Medical Press accepts no liability in respect of the content of any letter, nor is it responsible for the content and accuracy of any letter to the editor.

\section{Publish your work in this journal}

Clinical Interventions in Aging is an international, peer-reviewed journal focusing on evidence-based reports on the value or lack thereof of treatments intended to prevent or delay the onset of maladaptive correlates of aging in human beings. This journal is indexed on PubMed Central, MedLine,
CAS, Scopus and the Elsevier Bibliographic databases. The manuscript management system is completely online and includes a very quick and fair peer-review system, which is all easy to use. Visit http://www.dovepress. com/testimonials.php to read real quotes from published authors. 